\title{
A Study on the Asymmetric Effect to Housing Market Price Volatility
}

\author{
Chasoon Choi \\ Department of Real Estate Studies, Namseoul University, Cheonan-Si, Chungnam, Korea \\ Email address: \\ chasoon59@nsu.ac.kr \\ To cite this article: \\ Chasoon Choi. A Study on the Asymmetric Effect to Housing Market Price Volatility. International Journal of Business and Economics \\ Research. Vol. 8, No. 6, 2019, pp. 406-413. doi: 10.11648/j.ijber.20190806.21
}

Received: October 18, 2019; Accepted: November 20, 2019; Published: November 25, 2019

\begin{abstract}
The objective of this paper empirically analyzes the relations between information and housing market volatility using the housing price index of Seoul, San Francisco and Los Angeles for the time period from January 1995 to July 2019. For the empirical test of the asymmetric effect of information on housing market volatility, this paper employs GJR-GARCH model which enable good information and bad information to have impact on volatility. The analysis results are as follows. First, it was found that the GJR-GARCH $(1,1)$ model is suitable for analyzing the asymmetric reaction of housing price volatility for information types. Second, it was found that for information types, Seoul, San Francisco, and Los Angeles all displayed asymmetric housing price volatility. It was found that Seoul reacted greater to volatility for unexpected positive earnings rate information than unexpected negative earnings rate information, while on the contrary, San Francisco and Los Angeles showed that they reacted greater to unexpected negative earnings rate information than to unexpected positive earnings rate information. These findings support the hypothesis. Third, for sensitivity to volatility, Seoul was found to be about five times higher than San Francisco and Los Angeles. It is necessary to differentiate the housing price volatility prediction model and portfolio composition according to the information type.
\end{abstract}

Keyword: Housing Price, Volatility, Asymmetric Effect, Information, GJR-GARCH Model

\section{Introduction}

Housing is both consumer goods and investment goods. As a consumer goods, a house has the characteristics of a general good that provides residential services. On the other hand, housing as investment goods has the characteristics of financial products. In other words, if housing is used for investment purposes, the volatility of the housing market can be compared and analyzed even if the housing market is not adjacent due to the freedom of capital movement. Generally, price volatility of financial assets is known to react greatly to the flow of information, but volatility of housing prices is not very big. [1] But when considering how much percentage houses account for the national economy, the housing price volatility is in no way small. Volatility represents the risks of investments in terms of financial economics. [2] Volatility signifies risks in the housing market, and therefore, it is a very important variable for identifying the relationship of earnings rates and risks. Dynamic studies on the volatility of the housing market are lacking, but studies on the volatility of the stock market have been carried out by Ross (1989), Booth, Chowdhury, Martikainen and Tse (1997), Ng (2000), Pardo and Torro (2007), Kim and Kim (2008), Lee and Ohk (2015). [3-8] Black (1976) proposed asymmetric reaction of stock prices for information claiming that stock price volatility reacts more sensitively to bad news than good news. [9] However, A hypothesis can be set that the housing market shows greater housing price volatility when the economy is improving thus resulting in speculative investments, but when the economy slows down, it results in a lock-in-effect that leads to decrease housing price volatility. The identification of this hypothesis can provide important information for strategic investment, portfolio management and real estate policy. This study begins with the necessity of academic testing of this hypothesis, and further has a practical purpose of predicting housing returns. Also, it will be able to provide basic information for verifying the efficient market hypothesis of the housing market and for housing market stabilization policies. As a model for analyzing the volatility of the housing market, we will use 
the GJR-GARCH model, which is frequently used in financial time series research. The GJR-GARCH model is suitable for analyzing asymmetric volatility of information. In this study, the condominium price index of Seoul, San Francisco and Los Angeles was used to analyze the asymmetric volatility of the housing market for information. This study is unique in that it is the first attempt at analyzing asymmetric reaction of volatility according to information type for the housing markets of Korea and the USA. This study is comprised as follows. Chapter II examines preceding studies, Chapter III examines the analysis models, namely GJR-GARCH $(1,1)$ model and GARCH $(1,1)$ model, Chapter IV presents the analysis results according to the analysis model, and Chapter V contains the conclusion.

\section{Literature Review}

Studies on asymmetric reactions have mainly focused on financial time series such as stocks, exchange rates, interest, etc., but there are few studies on price volatility asymmetric reactions on the housing market. French, Scwert and Stambaugh (1987) stated that asset price volatility is bigger in times when there are transactions compared to times when there are no transactions. Volatility has bigger impact because there is higher possibility that public and private information can reach the asset market, therefore affecting investment decisions. In addition, it was reported that volatility occurs because of pricing errors among transactions. [10] Campbell and Hentschel (1992) analyzed the relationship of stock earnings rates and volatility. Upon analysis, it was claimed that stock market risk premiums had positive correlation with expected stock earnings rate volatility. Furthermore, they claimed that unexpected stock earning rates had a negative correlation with negative volatility. [11] Dolde and Tirtiroglue (2002) analyzed that 36 volatility factors were important in regional housing price volatility using the GARCH model. Most volatility factors are regional factors, but three of them were national. Economic status, national and regional income growth, and inflation and interest rate had a big impact on volatility. It was reported that volatility of regional housing prices spread regionally but do not decrease. In particular, it said that new insight is needed for mortgage investors and general investors for the economic situation, housing price volatility and earnings rates. [12] Crawford and Fratantoni (2003) used the ARIMA, GARCH, and Markov Switching model to make comparative analyses on housing price predictability for the five US states of California, Florida, Massachusetts, Ohio and Texas and claimed that the GARCH model has high predictability. [13] Miller and Peng (2006) used 277 MSA (metropolitan statistical area) housing price indices with the VAR model to analyze the volatility and dynamic relationship of detached house value. Analysis results showed that detached house value volatility was greatly affected by external elements such as population growth rates, and it was analyzed that increased income growth rate per person actually lowered volatility. Furthermore, it reported that the MSA housing market had strong heteroskedasticity. [14] Miles (2008) used the quarterly housing price index from Q1 of 1979 to Q2 of 2006 of the OFHEO (Office of Federal Housing Enterprise Oversight) to analyze the GARCH effects in the 50 states of the United States. Analysis showed that over half of the 50 states had GARCH effects. [15] Lee (2009) used quarterly data from Q4 of 1987 to Q4 of 2007 in eight cities using the EGARCH model to investigate the deciding factors of housing price volatility in Australia. Analysis showed that the EGARCH model was highly suitable for presuming the housing price volatility factors and it was reported that the volatility deciding factors of each city and the volatility clustering effects occurred in multiple cities. [16] Kim (2009) used the GJR (1,1)-M model to analyze the mutual transition effect on price volatility by risk assets such as stocks, bonds and real estate. The results of the analysis reported that Korea's stock market affected the volatility of the bond market and real estate market, and that it possessed the most independent volatility. Meanwhile, it was analyzed that the volatility of the bond and real estate market did not affect volatility of the stock market, and that it was actually affected by the volatility of the stock market. However, because volatility of the stock and bond market became mutually transitional following the foreign exchange crisis, the independence of the stock market is disappearing, while the real estate market was analyzed to be changing into an independent market from the volatility shock of other asset markets. [17] Willcocks (2010) analyzed regional volatility of housing prices with the GARCH model and EGARCH model using quarterly housing price indices from Q4 of 1973 to Q4 of 2007 for 13 cities in England. Based on the analysis, it was reported that $\mathrm{ARCH}$ effects appeared in seven out of 13 cities and EGARCH effects appeared in 6 out of 13 cities. [18] Tian and Gallagher (2015) stated that big volatility in housing prices was experienced in the Chinese market from 2005 to 2013. In order to empirically analyze whether the cause of such volatility was due to the inflow of short-term external funds or because of the Chinese government's capital market regulations, monthly data from December of 1998 to October of 2013 were analyzed. Results of the analysis showed that the inflow of short-term external capital did have an effect on raising the volatility of housing prices, but it was identified that in the long-run, the capital regulation of the Chinese government had contributed to decreasing housing price volatility to some extent. [19] Lee, Lee, and Jung, (2015) used the cluster-type verification model and quantile regression model to conduct a comparative analysis on whether the clustering of the apartment market was manifested with the stock market. Results of the analysis showed that clustering did not appear in large capital stock, but it did in the apartment market. They analyzed that it was asymmetrical where clustering did not manifest when the apartment market dropped and clustering occurred when it rose. It was revealed that there was a difference with the general drop that occurred in the stock market. [20] Lee and Lee (2016) analyzed whether asymmetric volatility exists in the large-cap, mid-cap and 
small-cap stock indices of the Korea Stock Exchange. Smallvolatility volatility is more likely to respond to adverse information than large-volatility volatility. [21] Kim and Lee (2016) analyzed the mutual impact of the returns between the real estate and stock markets using GARCH-BEKK model. The results show that the shock transition through the symmetric model has a significant positive influence from the real estate market to the stock market. The asymmetric model also analyzed that the impact of the downturn in the real estate market exerted a significant positive impact on the stock market. [22] Fernández (2017) used the column crosssection of corporate earnings and market participants to analyze the sales transfer effects from one convenience facility to another convenience facility in cities in the Netherlands. In result, it was analyzed that the entry of bars had transfer effects of profitability for take-out businesses, but there were no opposite transfer effects. [23] Park and Kim (2017) classified the metropolitan area into eight subregions and conducted an empirical analysis on the coupling and transfer of volatility of housing prices. The analysis shows that volatility in housing prices has shifted from the Gangnam area of Seoul to other areas of the metropolitan area. [24] When examining earlier studies as such, there are still few studies on the asymmetric reactions of domestic and foreign housing market volatility. Therefore, this study aims at conducting an empirical analysis on the asymmetric reaction of housing market price volatility in Seoul, San Francisco, and Los Angeles to propose a housing price prediction model.

\section{Data and Research Method}

\subsection{Analysis Model}

There are various models that analyze asymmetric reaction of information, but in this study, Glosten et al.'s (1989) GJRGARCH model was used as the representative model. [25] According to the Monte Carlo simulation analysis results of Engle and $\mathrm{Ng}$ (1993), the GJR-GARCH model has been verified as the best research methodology for analyzing asymmetry of volatility for information. [26] First, the GJRGARCH $(1,1)$ model is as shown in Equation (1).

$$
\begin{gathered}
R_{t}=\mu+\rho R_{t-1}+e_{t} \\
e_{t}=\left|\Omega_{t-1}\right| \sim N\left(0, h_{t}\right) \\
h_{t}=\omega+\alpha e_{t-1}^{2}+\gamma S_{t-1}^{-} e_{t-1}^{2}+\beta h_{t-1} \\
\text { Where } S_{t-1}^{-}=\left\{\begin{array}{l}
1, e_{t-1}<0 \\
0, e_{t-1} \geq 0
\end{array}\right.
\end{gathered}
$$

In Equation (1), $R_{t}$ is the monthly earnings rate of housing prices and the coefficient $\rho$ value being significant means that the rise or falling trend of housing prices will continue in the following month as well. $\Omega_{t-1}$ means the group of all information to t-1. $e_{t} e_{t-1}$ shows new information groups for each time point and when $e_{t} e_{t-1}$ is positive (+) it represents good information and when negative (-) it represents bad information. When the information is good, it shows a rise in housing price earning rates and when it is bad, it shows a drop in housing price earnings rates. $h_{t}$ represents conditional variance. $S_{t-1}^{-}$is a dummy variable for representing the asymmetry of information and if the value of $e_{t-1}$ is (-) then it is one and if the value of $e_{t-1}$ is positive then it is 0 . Therefore, $S_{t-1}^{-} e_{t-1}^{2}$ represents asymmetry of housing prices. If coefficient $\gamma$ represents a positive value, then it means that the negative $e_{t-1}$ (bad news) of t-1 term can further increase volatility of conditional housing prices of the t term compared to positive $e_{t-1}$ (good news). $\beta$ is the coefficient that shows the continuity of volatility. This study used the nonlinear optimization technique that maximizes log likelihood function based on the BHH algorithm of Berndt, Hall, Hall, and Hausman (1974) to find the parameter maximum likelihood estimate of the GJR-GARCH model and GARCH model. [27]

Furthermore, changes of housing price earnings rate volatility of Korea and US depending on time were compared and the symmetric reaction model, GARCH model, was also analyzed to compare with the estimated parameter values of asymmetric response. The GARCH model is the model that Bollerslev (1986) generalized using the ARCH (Autoregressive Conditional Heteroscedasticity) model introduced by Engle (1982). [28, 29] The GARCH model added the time difference of conditional variance in the ARCH model, The GARCH $(1,1)$ model is as shown in Equation (2).

$$
\begin{aligned}
& R_{t}=\mu+\rho R_{t-1}+e_{t} \\
& h_{t}=\omega+\alpha e_{t-1}^{2}+\beta h_{t-1}
\end{aligned}
$$

As the explanatory variable of the mean equation $R_{t}$ of Equation (2), $R_{t-1}$ that corresponds to AR (1) was inserted. Conditional variance equation $h_{t}$ is shown with constant $\omega$, error squared of the previous term $e_{t-1}^{2}$ and the equation of conditional variance $\sigma_{t-1}^{2}$. Coefficient $\alpha$ shows the sensitivity of volatility and $\beta$ shows the continuity of volatility. The $\alpha+\beta$ value is the coefficient that shows the time fluctuation of housing price volatility and when the coefficient nears 1 , it means that the current volatility has a high possibility to continue in the future. In other words, it means that when the estimates of $\alpha$ and $\beta$ both have statistically significant positive values, it is possible to estimate the time fluctuation of the housing price volatility with the GARCH $(1,1)$ type model. However, the GARCH $(1,1)$ model has limitations in that it cannot analyze asymmetric reaction of information.

In order to verify the feasibility of the maximum likelihood estimator and the model, it is verified with the most commonly used LR (likelihood ratio) statistics. For this, when the GARCH $(1,1)$ model's null hypothesis is said to be $\mathrm{L}\left(H_{0}\right)$ (here, $\left.H_{0}: \mu, \rho, \omega, \alpha, \beta\right)$ and the GJR-GARCH $(1,1)$ model's alternative hypothesis is $\mathrm{L}\left(H_{a}\right)$ (here, $\left.H_{a}: \mu, \rho, \omega, \alpha, \beta\right)$, $\mathrm{LR}=2\left[\left(H_{a}\right)-\left(H_{0}\right)\right]$ achieves asymptotic $x_{n}^{2}($ here, $\mathrm{n}=1)$ distribution. At this time, if the value of the estimated LR verification statistical value is larger than the $x_{n}^{2}$ statistical value, then the null hypothesis dismissed. 


\subsection{Data}

Data used for this study are the apartment price index of Seoul investigated and announced by the Korea Appraisal Board and the condominium (in Korea, condominiums are called apartments) price index of San Francisco and Los Angeles published by the Federal Reserve Bank of St. Louis. The usage period of data was used through seasonal adjustment of monthly data from January 1995 to July 2019 when monthly time series data could be obtained. The reasons for choosing these regions were similar in volatility in the housing price index during the analysis period (1995 to July 2019), except during the global financial crisis (2008 to 2013). Therefore, it was judged that it is easy to observe asymmetric variability of information.

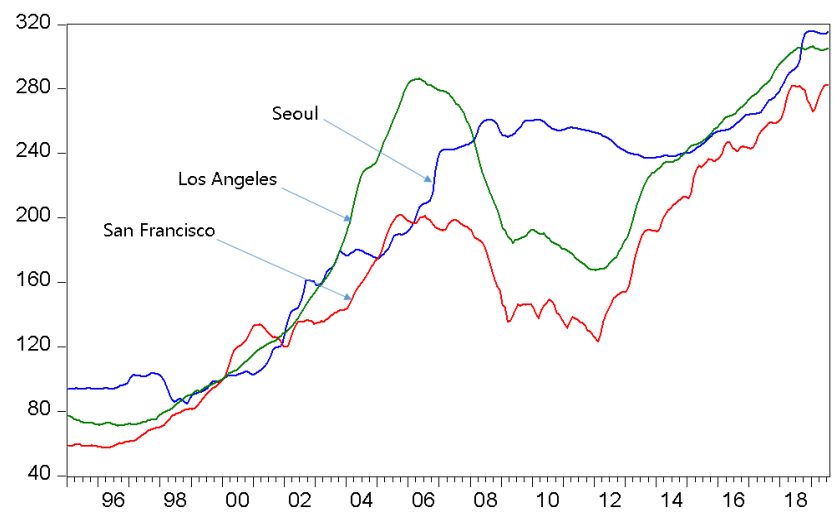

Figure 1. Apartment Price Trends in Seoul, San Francisco and Los Angeles.

\section{Discussion of Results}

\subsection{Statistical Features of Price Index Earnings Rates of Each Housing Market}

The apartment price earnings rate $\left(R_{t}=\ln \left(P_{t} / P_{t-1}\right)\right)$ was calculated by acquiring the natural from the apartment price index and categorizing them, and the basic statistics of the earnings rate are as shown in Table 1. The earnings rate of apartment prices was slightly high for San Francisco at 0.005 and Seoul and Los Angeles were similar at about 0.004 , and it was found that the standard deviation was similar for Seoul and Los Angeles, while it was high for San Francisco at 0.0133, showing higher uncertainty. Skewness was positive $(+)$ for Seoul and negative (-) for both San Francisco and Los Angeles, showing a more leftward tendency than regular distribution, and it was found that kurtosis was 3.6445 for Los Angeles, while it was larger than 6 for both Seoul and San Francisco, thereby showing much sharper spinode than regular distribution. Also, the Jarque-Bera statistics dismiss the null hypothesis that the housing price fluctuation rate distribution is in regular distribution at a $1 \%$ significance level, and therefore, it is evident that ARCH-type model setting can be applied according to heteroscedasticity.
Table 1. Apartment price earnings rate base statistics.

\begin{tabular}{llll}
\hline & Seoul & San Francisco & Los Angeles \\
\hline Average & 0.0041 & 0.0052 & 0.0046 \\
Standard deviation & 0.0109 & 0.0133 & 0.0109 \\
Skewness & 1.2159 & -0.9772 & -0.3120 \\
Kurtosis & 9.9379 & 6.3635 & 3.6445 \\
Jarque-Bera & 662.10 & 185.38 & 9.85 \\
statistics & $(0.0000)$ & $(0.0000)$ & $(0.0072)$ \\
\hline
\end{tabular}

Note: ( ) is a significance level where the null hypothesis can be dismissed.

Meanwhile, the time series analysis is based on stationary. Therefore, in order to verify the stationary of variables, ADF (Augmented Dickey-Fuller) verification and unit root verification through PP verification was conducted. [30, 31] The results are as shown in Table 2 and the time series data for primary categorization of logs for each index was found to be $5 \%$ for Los Angeles and 1\% for the remaining, thus being stationary.

Table 2. Unit root verification results.

\begin{tabular}{llll}
\hline & & Original index & Log categorization \\
\hline \multirow{2}{*}{ ADF } & Seoul & -0.2729 & $-7.8775^{* * *}$ \\
$(\operatorname{lag} 1)$ & San Francisco & -0.1174 & $-4.7656^{* * *}$ \\
& Los Angeles & -1.1556 & $-2.8501^{* *}$ \\
& Seoul & -0.2729 & $-7.8775^{* * *}$ \\
PP (lag1) & San Francisco & -0.2660 & $-8.1174 * * *$ \\
& Los Angeles & -0.7473 & $-3.7201 * * *$ \\
\hline
\end{tabular}

Note: 1. $\mathrm{p}<0.01^{* * *}, \mathrm{p}<0.05^{* *}, \mathrm{p}<0.1 \times 2$. When including constant term, significance level is $1 \%$ threshold is 3.45 .

\subsection{Asymmetric Effect of Housing Price Volatility}

Results of analyzing the GARCH $(1,1)$ model and GJRGARCH $(1,1)$ model of the housing price index earnings rate are as shown in Table 3 and Table 4 . The reason why the symmetric GARCH $(1,1)$ model estimate was first presented in Table 3 was to examine whether the volatility of housing price index earnings rate of Korea and the US change with the change of time and to compare the asymmetric GJRGARCH $(1,1)$ model estimates. When looking at the estimate results according to the GARCH $(1,1)$ model, the Seoul housing market's mean equation constant term $\mu$ and conditional dispersion equation constant term $\omega$, and Lost Angeles housing market's conditional dispersion equation constant term $\omega$ are not significant, while all other coefficients were found to be statistically significant at levels under $5 \%$. The first time-difference coefficient $\rho$ has a positive $(+)$ sign and when it is statistically significant at levels below $1 \%$, it means that the rises or drops in housing prices in Seoul, San Francisco, and Los Angeles would continue in the following month as well. It was found that the coefficients $\alpha$ and $\beta$ that show sensitivity and continuity of volatility are statistically significant at the $1 \%$ level. This means that the GARCH-type models are appropriate models for estimating the time change of housing price volatility. Sensitivity volatility $\alpha$ was 0.8539 for Seoul and, 0.1820 for San Francisco and 0.0988 for Los Angeles, thus showing that Seoul's housing market was about five times higher than those of San Francisco and Los Angeles. This means that 
during the sample period, Seoul's housing market is more relatively more sensitive to information compared to the housing markets of San Francisco and Los Angeles. It was found that the coefficient $\alpha+\beta$ value that shows the continuity of volatility was found to be larger for San Francisco and Los Angeles by more than 1 compared to Seoul, thus demonstrating that Seoul would have longer volatility than San Francisco and Los Angeles.

Table 3. Symmetric effect of the GARCH $(1,1)$ model housing market.

\begin{tabular}{|c|c|c|c|c|c|c|}
\hline \multirow{2}{*}{ Statistics } & \multicolumn{2}{|l|}{ Seoul } & \multicolumn{2}{|l|}{ San Francisco } & \multicolumn{2}{|l|}{ Los Angeles } \\
\hline & Coefficient value & z statistics & Coefficient value & z statistics & Coefficient value & $\mathrm{z}$ statistics \\
\hline$\mu\left(\times 10^{2}\right)$ & -0.0310 & -0.4521 & 0.7322 & $4.1971 * * *$ & 0.5136 & $2.8981 * * *$ \\
\hline$\rho$ & 0.7773 & $18.9694 * * *$ & 0.7140 & $15.7956^{* * *}$ & 0.8534 & $31.7695 * * *$ \\
\hline$\omega\left(\times 10^{2}\right)$ & 2.19E-05 & 1.01889 & 7.39E-04 & $1.9717 * *$ & $1.29 \mathrm{E}-05$ & 0.5621 \\
\hline$\alpha$ & 0.8539 & $9.5109 * * *$ & 0.1820 & $3.5146^{* * *}$ & 0.0988 & $3.4707 * * *$ \\
\hline$\beta$ & 0.5297 & $19.5736 * * *$ & 0.7402 & $8.7594 * * *$ & 0.8970 & $32.0600 * * *$ \\
\hline Log likelihood value & 1127.936 & & 972.841 & & 1128.798 & \\
\hline
\end{tabular}

Note: $1 . * * * * *, *$ shows significance at $1 \%, 5 \%, 10 \%$ levels, respectively.

In order to analyze the symmetric reactions of unexpected negative (-) earnings rate (drop in housing prices due to bad news) and unexpected positive $(+)$ earnings rate (rise in housing prices due to good news) that affect housing price volatility in the GARCH $(1,1)$ model, the estimation results of the GJR-GARCH $(1,1)$ model that added $S_{t-1}^{-} e_{t-1}^{2}$ in GARCH are as shown in Table 4. Coefficient $\gamma$ that shows the symmetric reaction of the GJR-GARCH $(1,1)$ model was found to be statistically significant at under the $5 \%$ level for the Seoul housing market with negative (-) sign and for the San Francisco and Los Angeles housing market with positive (+) sign. Such results mean that in the case of the Seoul housing market, unexpected positive earnings rate increase housing price volatility more than unexpected negative earnings rate. However, in the case of the housing market of
San Francisco or Los Angeles, it was found that unexpected negative earnings rate increased housing price volatility more than unexpected positive earnings rate. In other words, it is evident that impact of information on housing price volatility is asymmetrical. This is attributable to the regionality of the housing market. An efficient market hypothesis can be set for the housing markets of Seoul, San Francisco, and Los Angeles. According to the above analysis, Seoul supports the hypothesis, but San Francisco and Los Angeles do not. This means that it is necessary to differentiate when means that it is necessary to differentiate when predicting housing price volatility according to the types of information such as economic environment, population, preference, anticipation, etc. of the housing market.

Table 4. Asymmetrical effect of the GJR-GARCH $(1,1)$ model housing market.

\begin{tabular}{|c|c|c|c|c|c|c|}
\hline \multirow{2}{*}{ Statistics } & \multicolumn{2}{|l|}{ Seoul } & \multicolumn{2}{|l|}{ San Francisco } & \multicolumn{2}{|l|}{ Los Angeles } \\
\hline & Coefficient value & z statistics & Coefficient value & z statistics & Coefficient value & z statistics \\
\hline$\mu\left(\times 10^{2}\right)$ & 0.0682 & 0.7690 & 0.6121 & $3.3946 * * *$ & 0.0042 & $2.0597 * *$ \\
\hline$\rho$ & 0.8164 & $19.6043 * * *$ & 0.72198 & $16.7566 * * *$ & 0.8633 & $32.7802 * * *$ \\
\hline$\omega\left(\times 10^{2}\right)$ & $1.82 \mathrm{E}-05$ & 1.0678 & $9.82 \mathrm{E}-04$ & $2.2656^{* *}$ & $1.15 \mathrm{E}-05$ & 0.4948 \\
\hline$\alpha$ & 0.8979 & $8.3596 * * *$ & 0.0117 & 0.2975 & 0.0465 & $2.6460 * * *$ \\
\hline$\gamma$ & -0.4957 & $-3.8014 * * *$ & 0.2787 & $2.4150 * * *$ & 0.0849 & $1.9271 * *$ \\
\hline$\beta$ & 0.6033 & $27.4563 * * *$ & 0.7329 & $8.7118 * * *$ & 0.9114 & $37.0077 * * *$ \\
\hline LR statistics & $7.632 * *$ & & $11.022 * * *$ & & $4.65 *$ & \\
\hline
\end{tabular}

Note: $1 . * * *, * *, *$ : significant at $1 \%, 5 \%, 10 \%$ levels, respectively.

2. $x_{1}^{2}$ statistics at $10 \%, 5 \%, 1 \%$ significance levels are $3.841,5.024,7.879$, respectively.

When examining the log-likelihood after estimating the GARCH $(1,1)$ model and GJR-GARCH $(1,1)$ model to verify the feasibility of models, it is evident that compared to when using the GARCH $(1,1)$ model, the log likelihood value of the GJR-GARCH $(1,1)$ model that includes the dummy variable $S_{t-1}^{-} e_{t-1}^{2}$ that catches information asymmetry is generally higher. The LR statistics of the GJR-GARCH $(1,1)$ model was higher than the $x_{1}^{2}$ statistics, thus dismissing the null hypothesis at under the $10 \%$ level for Seoul, San Francisco, and Los Angeles. Therefore, it is evident that the GJR-GARCH $(1,1)$ model that can capture asymmetric reaction is more feasible than the GARCH $(1,1)$ model that can capture symmetric reaction.

\subsection{Relationship of Unexpected Earnings Rate and Conditional Volatility}

The question on whether the reaction on the volatility of housing price earnings rate is symmetrical or asymmetrical depending on the type of information to reach the housing market of Seoul, San Francisco, and Los Angeles will be examined. The size of the unexpected housing price volatility in the GARCH $(1,1)$ model is indicated as $\alpha$ and in the GJRGARCH $(1,1)$ model, it is indicated as the size of $\alpha$ and $\gamma$. When examining the GARCH $(1$,$) model analysis results of$ Seoul and San Francisco in Table 3, for Seoul, $\alpha$ is 0.8539 and therefore, $85.39 \%$ of $e_{t-1}^{2}$ affected $\mathrm{t}$ term conditional volatility $h_{t}$ and for San Francisco, $\alpha$ was 0.0117 and therefore, $1.17 \%$ of $e_{t-1}^{2}$ affected $\mathrm{t}$ term conditional 
volatility $\mathrm{h}_{\mathrm{t}}$. Therefore, it shows that Seoul's $e_{t-1}^{2}$ on $\mathrm{t}-1$ term gives much greater effect on $t$ term conditional volatility $h_{t}$ than that of San Francisco. This means that compared to San Francisco, it would be much easier to predict the housing price volatility for Seoul. When examining the GJR-GARCH $(1,1)$ model analysis results in Table 4, Seoul showed $\alpha, \gamma$ estimates of 0.8979 and -0.4957 , respectively, and thus, in the case of unexpected positive $(+)$ earnings rate $(\alpha)$ it was 0.8979 , and thus, $89.79 \%$ affected $\mathrm{t}$ term conditional volatility, while the unexpected negative (-) earnings rate $(\alpha+\gamma)$ was -0.4022 , thus showing that $-40.22 \%$ affected the conditional volatility of $t$ term. For San Francisco, the $\alpha, \gamma$ estimates were 0.0117 and 0.2787 , respectively, and the unexpected positive $(+)$ earnings rate $(\alpha)$ was 0.0117 , thus showing that $1.17 \%$ had conditional volatility of $t$ term and in the case of unexpected negative (-) earnings rate $(\alpha+\gamma)$, it was 0.2904 , thus showing that $29.04 \%$ affected the conditional volatility of t term. An interesting discovery here is that in the case of the housing market of Seoul, it reacted more asymmetrically to unexpected positive $(+)$ earnings rate $(\alpha)$ information compared to unexpected negative (-) earnings rate $(\alpha+\gamma)$ information, and that in the case of San Francisco and Los Angeles, it reacted more asymmetrically to unexpected negative (-) earnings rate $(\alpha+\gamma)$ information. When looking at the results of such analysis, it is evident that the asymmetrical reaction of housing price volatility is significantly larger depending on whether the information that reaches the housing market is good news or bad news. The GJR-GARCH $(1,1)$ model analysis results also show that the $\mathrm{t}$ term $e_{t-1}^{2}$ had much greater impact on conditional volatility $h_{t}$ of $t$ term for Seoul compared to San Francisco or Los Angeles.

Furthermore, the relationship of unexpected earnings rate $\left(e_{t-1}\right)$ and conditional volatility $\left(h_{t}\right)$ regarding the asymmetrical reaction of housing price volatility for Seoul, San Francisco, and Los Angeles were drawn as a graph and shown in Figure 2 and Figure 4. Figure 2 is the graph that shows the asymmetric reaction of the housing price volatility of Seoul estimated with the GJR-GARCH $(1,1)$ model, and as explained earlier, it shows that it reacts more asymmetrically to unexpected positive $(+)$ earnings rate information than unexpected negative (-) earnings rate information. This is interpreted that in the housing market of Seoul, there is a studying effect of anticipation that even if the housing price drops momentarily, the price of the asset that is the house will one day rise again, so people hold off on liquidating the house and thus, investment demand rises when housing prices rise. However, in the case of San Francisco or Los Angeles estimated with the GJR-GARCH $(1,1)$ model, it was found that housing price volatility reacted more asymmetrically to unexpected negative (-) earnings rate than unexpected positive $(+)$ earnings rate as shown in Figure 3 and Figure 4. Such results mean that in the United States, houses are also treated as an alternative investment product like stocks and bonds more than in Korea, and thus, the level of asymmetry had a stronger impact for unexpected negative information. Such results mean that in the United States, houses are also treated as an alternative investment product like stocks and bonds more than in Korea, and thus, the level of asymmetry had a stronger impact for unexpected negative information. This implies that it is necessary to differentiate whether the information that arrives in the housing market is good news or bad news when predicting the housing price volatility for the housing market just like the stock market.

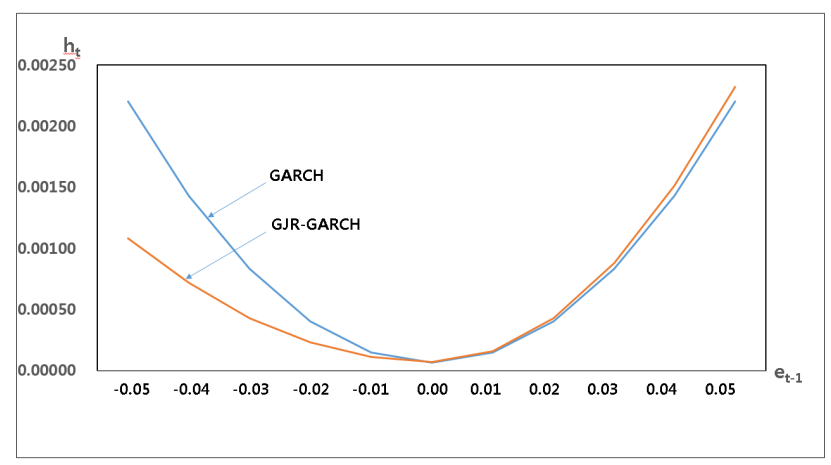

Figure 2. Asymmetric effect of housing price volatility in Seoul.

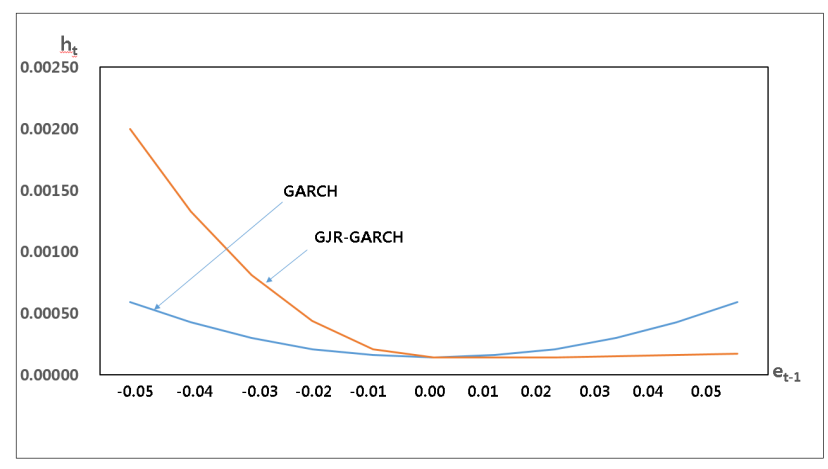

Figure 3. Asymmetric effect of housing price volatility in San Francisco.

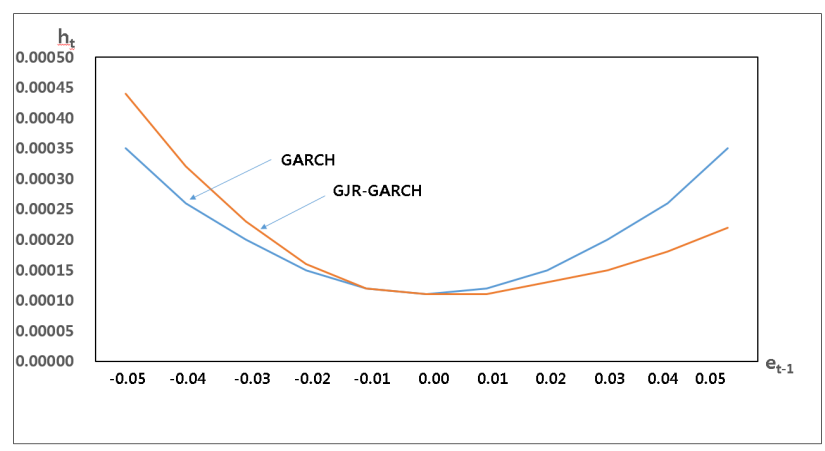

Figure 4. Asymmetric effect of housing price volatility in Los Angeles.

\section{Conclusion and Recommendations}

In this study, an empirical analysis was conducted on the asymmetrical response of housing price volatility for information types using the GRJ-GARCH $(1,1)$ model using the housing price indices of Seoul, San Francisco, and Los Angeles. The analysis results are as follows. First, it was found that for analyzing asymmetric reaction of housing price volatility for information types, the LR statistics of the GJR-GARCH $(1,1)$ model was higher than that of the GARCH $(1,1)$ model, and thus being more appropriate. This means that the GJR-GARCH models are normally used for analyzing asymmetrical reactions of financial time-series 
data such as stocks and bonds, and it was also found that it is possible to use the asymmetrical reaction of housing price volatility for analysis. It was thus judged that it could be used as the prediction model for housing price volatility. Second, it was found that Seoul, San Francisco, and Los Angeles all displayed asymmetrical housing price volatility depending on the information types. However, coefficient $\gamma$ that shows the asymmetrical reaction of the GJR-GARCH $(1,1)$ model was found to be statistically significant at levels under 5\% for negative (-) in the Seoul housing market and positive $(+)$ for the San Francisco and Los Angeles housing markets. This means that for the housing market of Seoul, unexpected positive earnings rate amplified housing price volatility more than unexpected negative earnings rate, and on the other hand, in the case of the housing market of San Francisco and Los Angeles, it means that unexpected negative earnings rate increased housing price volatility more than unexpected positive earnings rate. In other words, it shows that the impact of information on housing price volatility is more asymmetrical. Such analysis results can be interpreted that in the housing market of Seoul, there is an anticipated achievement effect that even if the housing price drops momentarily, the price of the asset that is the house will one day rise again, so people hold off on liquidating the house and thus, investment demand rises when housing prices rise. Meanwhile, in the case of San Francisco and Los Angeles, it is presumed that houses are treated as an alternative investment product like stocks and bonds. Third, volatility sensitivity $\alpha$ was 0.8539 for Seoul, 0.1820 for San Francisco, and 0.0988 for Los Angeles, showing that the housing market of Seoul was about five times higher than that of San Francisco or Los Angeles. This means that during the sample period, the housing market of Seoul was relatively more sensitive to information than the housing markets of San Francisco or Los Angeles.

When summarizing the above analyses, it was found that the housing market also displayed asymmetric volatility reaction to housing market information like the stock market.

These results are only limited to showing the dynamic relationship between the Seoul housing market and the San Francisco and Los Angeles housing markets based on a single housing price index time series. The housing market in Seoul responded more asymmetrically to good information, while the housing markets in San Francisco and Los Angeles responded asymmetrically to bad information. It cannot be concluded that this is the general phenomenon in the housing market. Because, such asymmetric effects on information does not apply uniformly due to the localization and specificity of the housing market, and they differ by region and country. Despite these limitations, the analysis results of the asymmetrical effects of the housing market on information will provide new insights for Korean policymakers, It is expected to contribute to the diversification of portfolios according to the type of information and to the understanding of the return forecasts for investors who participate in the market to obtain the return on investment. Follow-up studies using precise research methods using further expanded macroeconomic materials are needed for the soundness of this study.

\section{Acknowledgements}

Funding for this paper was provided by Namseoul University.

\section{References}

[1] Lim, J. M. (2006). A Study on the Volatility of Housing sales Prices. Housing Studies Review, 14 (2), pp. 65-84.

[2] Kim, M. G. and Jang, K. H. (2003). Financial Economics (2), Seoul: Keyngmoonsa, pp. 201-202.

[3] Ross, S. A. (1989). Information and Volatility: The NoArbitrage Martingale Approach to Timing and Resolution Irrelevancy. The Journal of Finance, 44 (1), pp. 1-17.

[4] Booth, G. G., Chowdhury, M., Martikaien, T. and Tse, Y. (1997). Intraday Volatility in International Stock Index Futures Markets: Meteor Showers or Heat Waves? Management Science, 43, pp. 1564-1576.

[5] Ng, A. (2000). Volatility spillover effects from Japan and the US to the Pacific- Basin. Journal of International Money and Finance, 19 (2), pp. 207-233.

[6] Pardo, A. and Torro, H. (2007). Trading with Asymmetric Volatility Spillovers. Journal of Business Finance \& Accounting, 34 (9-10), pp. 1548-1568.

[7] Kim, J. R. and Kim, S. B. (2008). Information Flow Effect Between the Stock Market and the Foreign Exchange Market: An EGARCH Approach. Kukje Kyungje Yongu, 14 (1), pp. 111-135.

[8] Lee, M. K. and Ohk, K. Y. (2015). Market Anomalies and Multifactor Models: Comparison between the FF Model and the CNZ Model. Asia-Pacific Journal of Financial Studies, 44 (5), pp. 855-885.

[9] Black, F. (1976). Studies of Stock Price Volatility Changes. Proceedings of the 1976 Meeting of the Business and Economic Statistics Section. American Statistical Association, Washington DC, 177-181.

[10] French, K. R. Schwert, G. W. and Stambaugh, R. F. (1987). Expected Stock Returns and Volatility. Journal of Financial Economics., 19 (1), pp. 3-29.

[11] Campbell, J. Y. and Hentschel, L. (1992). No News is Good News: An Asymmetric Model of Changing Volatility in Stock Returns. Journal of Financial Economiccs, 31, pp. 281-318.

[12] Dolde, W. and Tirtiroglue, D. (2002). Housing Price Volatility Changes and Their Effects. Real Estate Economics, 30 (1), pp. 41-66.

[13] Crawford, G. W. and Fratantoni, M. C. (2003). Assessing the Forecasting Perfomance of Regime-Switching, ARIMA and GARCH Models of house Prices. Real Estate Economics, 30, pp. 223-243.

[14] Miller, N. and Peng, L. (2006). Exploring Metropolitan Housing Price Volatility. Journal of Real Estate Finance and Economics, 33 (1), pp. 5-18. 
[15] Miles, W. (2008). Volatility Clustering in U.S. Home Prices. Journal of Real Estate Research, 30 (1), pp. 73-90.

[16] Lee, C. L. (2009). Housing Price Volatility and its Determinants, Paper submission for presentation at The 15th Pacific Rim Real Estate Society Conference, Sydney, Australia, 18th - 21th January.

[17] Kim, M. H. (2009). Volatility Spillover Effects in Stock, Bond, and Real Estate Markets. The Association of Business Education, 53, pp. 329-347.

[18] Willcocks, W. (2010). Conditional Variences in UK Regional House Prices. Spatial Economic Analysis, 5 (3), pp. 339-354.

[19] Tian, Y. and Gallagher, K. P. (2015). Housing Price Volatility and the Capital Account in China, Boston University Global Economic Gorvernance Institute, Working Paper 2, July, pp. $1-31$.

[20] Lee, K. Y. Lee, J. A. and Jung, J. H. (2015). A comparison of herd behaviors between housing and equity markets - A focus of the assets with large market capitalization -. Korea Real Estate Review, 40, pp. 313-329.

[21] Lee, M. K. and Lee, S, K. (2016). An Examination on Asymmetric Volatility of Firm Size Stock Indices. The Korea Contents Association, 16 (8), pp. 387-393.

[22] Kim, B. J. and Lee, C. S. (2016). A Test on the Mutual Impacts between REITs and Stock Market in US. School Paper, 66, pp. 103-115.

[23] Fernández, R. (2017). Spillover effects and city development. https://editorialexpress.com/cgi-bin/.
[24] Park, Y. J. and Kim, K. H. (2017). Housing Price Comovements and Volatility Spillovers in Seoul Metropolitan Area. School Paper, 69, pp. 131-145.

[25] Glosten, L. Jagannathan, R. and Runkle, D. E. (1989). Relationship between the Expected Value and the Volatility of the Norminal Excess Return on Stocks. Working Paper, Department of Finance, Columbia University.

[26] Engle, R. F. and Ng, V. K. (1993). Measuring and Testing the Impact of News on Volatility. Journal of Finance, 48, pp. 1749-1778.

[27] Berndt, E. K. Hall, B. H. Hall, R. E. and Hausman, J. A. (1974). Estimation and Inference in Nonlinear Structural Models. Annals of Economic and Social Measurement. the National Bureau of Economic Research, 3 (4), pp. 653-665.

[28] Bollerslev, T. (1986). Generalized Autoregressive Conditional Heteroscedasticity. Journal of Econometrics, 31 (3), pp. 307327.

[29] Engle, R. F. (1982). Autoregressive Conditional Heteroskedasticity with Estimates of the Variance of U.K. Inflation. Econometrica, 50 (4), pp. 987-1008.

[30] Dickey, D. and Fuller, W. A. (1979). Distribution of Estimates for Autoregressive Time Series with a Unit Root. Journal of the American Statistical Association, 74, pp. 427-431.

[31] Phillips, P. C. and Perron, P. (1988). Testing for a Unit Root in Time Series Regression. Biometric, 75, pp. 335-346. 